\title{
Improving Social Skills through Structured Playfulness Program in Preschool Children
}

\section{Marina Tersi}

School of Physical Education and Sport Sciences of Democritus University of Thrace, Greece,Tmarina82@windowslive.com

\section{Ourania Matsouka}

School of Physical Education and Sport Sciences of Democritus University of Thrace, Greece, oumatsou@phyed.duth.gr

The purpose of this study was to examine the effect of a structured, playful activity program on the development of social skills in preschool aged children (46 years) during break time in the schoolyard of kindergarten. The participants were 40 pupils (26 toddlers and 14 pre-toddlers, 26 boys and 14 girls) from one Greek public kindergarten. Twenty (20) of them were set, as they were divided into their school classes, as control group (CG) and the rest 20, as experimental group (EG), who received activities intervention for four weeks (2 days a week). Data on children's social skills (cooperation, interaction, independence) and behavior problems (externalizing and internalizing) were collected from their teachers before and after interventional program, by completing the Preschool and Kindergarten Behavior Scale (PKBS-2, Merrell, 2002). The results indicated that both groups exhibited significant improvement in the investigated social behaviors. Nevertheless, in the final measurement the intervention children showed significantly higher improvement in the externalizing problems than the control group. The findings highlight the need for early detection of developing behavioral problems and the positive effect of a playful activity structured program in the schoolyard during breaks on the development of preschoolers' social skills.

Keywords: social skills, problem behaviors, preschoolers, assessment, intervention, schoolyard

\section{INTRODUCTION}

Scientific studies and clinical applications regarding children's social skills have become quite important since the 1980s, mainly due to the increasing recognition of the significant role of social development in children's overall well-being (Merrell \& Gimpel, 2014). Well-being has been defined as a "good life" by the WHO (2007),

Citation: Tersi, M., \& Matsouka, O. (2020). Improving Social Skills through Structured Playfulness Program in Preschool Children. International Journal of Instruction, 13(3), 259-274. https://doi.org/10.29333/iji.2020.13318a 
taking into account mental, physical and social aspects. Another reason for the surge of interest and popularity in children's social skills is that retrospective investigations have consistently shown strong relations between childhood social competence and social, academic and emotional functioning (Michelson et al., 2013; Wildenger \& McIntyre, 2012). More specifically, preschoolers' social skills are related to school readiness and adjustment (Denham, 2006; Rimm-Kaufman et al., 2000), in order to later succeed in academic achievement (McWayne et al., 2012; Oades-Sese et al., 2011) and to peer acceptance (Lindsey, 2002). In other words, entering a new and complex environment such as school leaves a deep impression on the children's realization and comprehension of laws. Preschool centers could be the first place in which the children experience separation from the family and they are positioned in a social environment outside home for the first time (Abdi, 2010; McClelland \& Morrison, 2003).

It has been stated that children with developed social skills are particularly preferred by peers and these types of children are more successful in their social life and academic school context (Arnold et al., 2012; Berry \& O'Connor, 2010), while children lacking social skills in the beginning of the school life may have peer rejection, academic failure and usually exhibit behavioral problems (Gulay, 2011; Langeveld et al., 2012). Peer relationships play an essential role in social skills (Merrell \& Gimpel, 2014). This view is reasonable because social reputation and the quality of one's social relations are often a result of how effectively one interacts socially with peers (Landau \& Milich, 1990; Oden \& Asher, 1977). Furthermore, a number of other studies have shown social skills and behavioral problems to be negatively correlated (Najaka et al., 2001). The interpretation of this relation is not obvious, however, such studies do indicate that low social skills and behavioral problems co-occur, and that even a causal relation can be assumed to exist between them. This means that is, low social competence could underlie behavioral problems (Langeveld et al., 2012; Merrell, 2002).

Developmental psychopathologists argued that most common behavioral problems in preschool children with poor social competence can be divided into two broad classes or dimensions-internalizing and externalizing problems (Poulou, 2015; Thomas \& Guskin, 2001). The internalizing dimension of behavioral problems includes symptoms of depression, social withdrawal, anxious and inhibited reactions, and the development of somatic problems that appears to be related to inner emotional distress (Merrell, 2001). The externalizing dimension consists of aggressive, defiant, disruptive oppositional, overactive and acting-out behaviors, which are predictive of serious conduct problems, disruptive behavior disorders and antisocial and delinquent behaviors (Shaw et al., 1994). Literature study shows that the development of social skills and problem behaviors often differ by gender, starting at early age (Abdi, 2010). While girls are more likely to possess higher social skills, boys have often more problem behaviors (DiPrete \& Jennings, 2012; Gomes \& Pereira, 2014; StØrksen et al., 2015; Vahedi et al., 2012), especially are more susceptible for externalizing problem behaviors than girls (Chiou, 2016; Maguire et al., 2016; Merrell, 2002; Merrell \& Gimpel, 2014). It has been stated that the observed sex differences might be an artifact of the interaction between biological sex differences and the environmental factors (Vahedi et al., 2012). 
Although, there is no single or unitary definition of social skills mostly due to the diversity of related traits, abilities, and behaviors, and to the complexity of the behaviorenvironment interaction necessary for their acquisition and performance (Merrell, 2008), Merrell and Gimpel (2014) concluded that "Social skills are learned, composed of specific behaviors, include initiations and responses, maximize social reinforcement, are interactive and situation-specific, and can be specified as targets for intervention" (p. 11). Early interventions can lead to positive interpersonal relationships and help prevent problem behavior and other life-damaging consequences (Ogden, 2011). Many researchers suggest that children who lack social skills may need to be trained in order to develop them through learning processes including observation, modeling, testing and receiving feedback (Gregoriadis, et al., 2013; O'Rourke \& Worzbyt, 1996). The enhancement of children's social skills is one of the most important goals of early childhood education (Gregoriadis et al., 2013; Serpell \& Mashburn, 2012). More specific the Greek Official Curriculum defines all pupils' social development as one of Greek education system's main goals (Cross-Curricular Program Framework, 2003)

Several socio-emotional skills development programs have been used in the preschool setting [e.g. I can Problem Solve (Chiou, 2016; Shure, 1980), Promoting Alternative Thinking Strategies curriculum - PATHS (Domitrovich et al., 2007), Second Step (Van Schoiack-Edstrom et al., 2002)] that emphasized on cognitive development by using different methodological designs which had high cost and required a lot of implementation time and additional training by kindergarten teachers in order to be involved in this process (Loukatari et al., 2014). However, the research in the existing literature demonstrated that social skills are further developed mostly through playful intervention and less through cognitive process (Loukatari et al., 2014; Rosenthal, 2003). Recent social development theories suggest that play provides an opportunity to children to practice different social roles and learn social rules (Bodrova \& Leong, 2015; Stagnitti, 2004).This literature review thus provided evidence to the fact that the teacher's structuring of play activities during the break in kindergarten is associated with high levels of social behavior in preschoolers children, greater acceptance of their peers and less frequent occurrence of antisocial behaviours (Loukatari et al., 2014; Sparris et al., 2016).

It is evident, therefore, that good measurement of social skills and problem behavior is important (Loukatari et al., 2014). Most researchers agree to six primary methods of collecting relevant information: behavioral observation, behavior rating scales, interviewing, self-report instruments, projective-expressive techniques and sociometric techniques (Merrell, 2001). According to Merrell (2001) naturalistic behavioral observation and behavior rating scales are the two best choices for social skills assessment. Several years ago, Elliott and Gresham (1987) proposed that "analyzing children's behavior in natural settings ... is the most ecologically valid method of assessing children's social skills" (p. 96). Research has also shown that behavior rating scales have become increasingly popular and are considered best practice as they are both effective and time-efficient (Merrell, 2008). Furthermore, as argues Merrell (2008), when rating scales completed by a teacher they are able to report a summation of a student's behavior over a wide range of characteristics based upon observations of a 
student over a long period of time. Also, since teacher's ratings are typically based upon an observation of the child over a long period of time, low incidence behaviors that are significant problems can be reported upon more easily. Finally, rating scales are advantageous because the ratings given by teachers of student's behavior utilize observations that are carried out in the normal classroom environment (Merrell, 2008).

Although there is evidence that social skills are developed mostly through playful intervention do in fact exist, only a few studies have been conducted to investigate the effects of these intervention among kindergarten children's social development.

\section{The Aim of the Study}

The purpose of this study was to examine the effect of a playful activity structured program on the development of social skills in preschool aged children (4-6 years) during break time in the schoolyard of kindergarten.

\section{METHOD}

The study used a quantitative research approach with experimental methods and was designed by using pretests-posttests and relevant control group.

\section{Participants}

The study took place in the school year of 2018-2019, between February and April and the participants were 40 normally-developing preschool age pupils ( 26 toddlers and 14 pre-toddlers, 26 boys and 14 girls) from a single public kindergarten school, which located in the city of Komotini, Northeastern Greece. This was a deliberate choice on the basis of availability. The selected kindergarten had two morning classes. Each classroom had 20 children from 4 to 6 years old and one female kindergarten teacher, who was familiar with her pupils across a 5-month period. This was a major advantage which was utilized when compiling the experimental and control groups. Pupils in the second class ( $\mathrm{n}=20,14$ boys and 6 girls) used as an experiment group (EG), that received games intervention for four weeks ( 2 days a week) under the control of their teacher, member of the co-authors in this study. At the same period pupils in the first class ( $n=20,12$ boys and 8 girls), as a control group (CG), followed their routine education program and free break time. Distribution of pupils per research group, with regard to gender and age, is shown in Table 1 below.

Table 1

Distribution of Participants ( $\mathrm{N}=40,100.00 \%)$

\begin{tabular}{llllllllll}
\hline Age & \multicolumn{2}{l}{ Experiment group } & \multicolumn{7}{l}{ Control group } \\
\hline & \multicolumn{2}{l}{ Boys } & \multicolumn{2}{l}{ Girls } & \multicolumn{2}{l}{ Boys } & \multicolumn{2}{l}{ Girls } & Total \\
& $\mathrm{f}$ & $\%$ & $\mathrm{f}$ & $\%$ & $\mathrm{f}$ & $\%$ & $\mathrm{f}$ & $\%$ & \\
\hline $\begin{array}{l}\text { Pre-toddlers (4-5 } \\
\text { years) }\end{array}$ & 5 & $12.5 \%$ & 2 & $5.0 \%$ & 5 & $12.5 \%$ & 2 & $5.0 \%$ & 14 \\
\hline Toddlers (5-6 years) & 9 & $22.5 \%$ & 4 & $10.0 \%$ & 7 & $17.5 \%$ & 6 & $15.0 \%$ & 26 \\
\hline Total & 14 & $35.0 \%$ & 6 & $15.0 \%$ & 12 & $30.0 \%$ & 8 & $20.0 \%$ & 40 \\
\hline
\end{tabular}

The fact that all the children from both groups attended the same kindergarten guaranteed a very similar environment, material resources and overall institutional 
philosophy. Therefore, it was possible to eliminate one of the core disruptive variables, consisting of the institution's different effect on children from the experimental group and children from the control group. Of course, despite the considerable similarity of these conditions, one must be aware of the different approaches by the teachers in the two classes. As the research involved minors, parents of all children were asked to give parental permission for their children to participate in the study. After personal talks with the school director and the teachers in the classes involved, oral consent was also obtained from the kindergarten.

It should be noted that in the Greek educational system kindergarten is part of the primary education and it is obligatory for pupils aged 4-6. Furthermore, kindergarten classes operate independently to a point, and each teacher submits her/his own daily program-which has to be in line with the Official Greek Curriculum-for approval to the director of kindergarten who is responsible for the day-to-day function of the educational institution he/she manages at every level. Additionally, the curriculum of early childhood education in Greece includes a 40-45 min period of break in daily basis, during which pupils play freely in the yard or in the classroom depending on the weather conditions. During this period of time, the students have the opportunity to rest and interact with each other and even more to develop their physical skills (Cross-Curricular Program Framework, 2003).

\section{Data Collection Tools}

For the purpose of the current research, the Preschool and Kindergarten Behavior Scales, Second Edition (PKBS-2, Merrell, 2002), after translating and testing its reliability and validity for the Greek population (Chiou, 2016) was used as a data collection instrument, which was filled out by the teacher in each class to evaluate children's behaviour, before and after the implementation of the program. The PKBS-2 is comprised of a total of 76 items separated into the Social Skills and Problem Behavior Scales. All items contain a 4-option Likert-type response ("Never", "Rarely", "Sometimes" and "Often"). The directions state: "It is recommended that individuals who rate the child...should have had the opportunity to observe and interact with the child for a minimum of 3 months before rating him or her using the PKBS-2." (Merrell, 2002).

The Social Skills scale includes 34 items that describe positive social skills that are characteristic of well-adjusted children aged 3-6 years and is divided into three broadband subscales: Social Cooperation, Social Interaction, and Social Independence. The Social Cooperation subscale is comprised of 12 items and reflects the child's ability to comply with adults and expectations of peer interactions (e.g. "Follows instructions from adults"). The Social Interaction subscale is comprised of 11 items relating to appropriate peer interactions critical for "gaining and maintaining acceptance and friendship from others" (Merrell, 2002) (e.g. "Comforts other children who are upset"). The Social Independence subscale is comprised of 11 items relating to social adjustment and confidence in the peer group domain as well as appropriate independence from adult caregivers (e.g. "Makes friends easily"). The Problem Behavior scale includes 42 items that describe various problem behaviors commonly seen among children aged 3-6 
years and is divided into two broad-band subscales: Externalizing and Internalizing Problems. The Externalizing Problems subscale is comprised of 27 items that reflect a child's disruptive and overactive behaviors (e.g. "Will not share"). The Internalizing Problems subscale is comprised of 14 items and reflects a child's emotional-behavioral problems (e.g.. "Is overly sensitive to criticism or scolding").

For Social Skills scale, the total score is obtained by summing the three subscales scores. Likewise, for Problem Behavior scale, the total score is obtained by summing the two subscale scores. Each subscale's score is the sum of the responses from its items. High scores from the general scale and from subscales indicate high level of social skills and problem behaviors while low scores point to low level of social skills and problem behaviours. The reliability of the original behavior scale (PKBS-2) was determined by Merrell (2002), who stated that the alpha and split-half coefficients for total scores ranged from 0.90 to 0.97 . Specifically, internal consistency reliability estimates for the social skills and problem behavior scales are .96 and .97 , respectively, test retest reliability estimates at 3-month intervals were found to be .69 and .78 (Merrell, 2002).

\section{Procedure and Intervention Program}

Prior to the beginning of the study, morning-class teachers were trained in order to familiarize themselves with the Greek version of the PKBS-2 and to implement it. To secure that both were scoring the same way, trial measurements with 12 pupils ( 9 toddlers and 3 pre-toddlers, 5 boys and 7 girls) were conducted. These children selected from the all-day class of the same kindergarten school that was not included in the study sample. The above procedure was carried out for two weeks. At the end of all the measurements, inter-rater reliability among the trained teachers was found $r_{\mathrm{ho}}=+.97$ on total 'Social Skills' (Social Cooperation: $\mathrm{r}_{\mathrm{ho}(10)}=+.95$, Social Interaction: $\mathrm{r}_{(10)}=+.98$, Social Independence: $\left.\mathrm{r}_{\mathrm{ho}(10)}=+.92\right)$ and $\mathrm{r}=+.99$ on total 'Problems Behavior' (Externalizing Problems: $\mathrm{r}_{\mathrm{ho}(10)}=+.99$, Internalizing Problems: $\mathrm{r}_{(10)}=+.98$ ).

After the above pilot study, the main experimental process followed in three phases: the initial measurement, the intervention program and the final measurement. In the first phase, over the period of two weeks, the experimental and control group teachers rated the social skills and behavior problems of each child, who belonged to their classroom, by observing naturalistically the students' behavior during their typical free break time in schoolyard. Straight afterwards, the experimental group participated in a 4-week structured, playful activity program during the period of break in kindergarten, whilst the children of the control group continued to follow their regular schedule and free break time. In the third phase, there was a new assessment of all the children, over the period of two weeks, which evaluated the effects of the intervention program. It took 15 to 20 minutes for each student to complete the PKBS-2 form. For a more effective examination of the children's behavior during the free play, the observations, during the pre- and post-measures, were recorded through videotaped. According to Gerrish and Lacey (2010), this method makes data collection more straight forward, limiting subjectivity and observer bias, while enhancing validity and reliability. 
Regarding the intervention program which aimed to develop social skills and improve certain behavioral problems, was performed during the period of break in kindergarten, for 4 weeks, two sessions per week and each session lasted 45 minutes. The participants worked either in heterogeneous groups of two to five members or all together $(n=20)$ on 2 structured playful activities per session. Examples of activities included the "Hula Hoop Pass", where the participants stand in a circle and hold hands. Start one hula-hoop hanging over one pair of joined hands. Each child in the circle must pass the hoop over $\mathrm{him} /$ herself and on the next child whilst staying connected at all times. In the other activity, "Catch the tail of kite" children line up with arms around the waist of the person in front. Last one has a handkerchief in his/her pocket. The child at the head of line tries to grab the handkerchief. No part of the "kite" may break. Additionally, "Tennis Ball Transfer" activity, which requires a large metal washer and a tennis ball for each group. The groups of 4 have to hold the strings and balance a tennis ball on the washer while walking and moving towards a plastic cup a distance away. Once the team successfully reaches the cup without dropping the ball they have to work together to figure out how to get the ball into the cup without touching either one. Some other activities were "Human table Football", "Pair and Group Stand up" e.g.

\section{Data Analysis}

The processing of the quantitative data that was collected, took place with the use of Statistical Package of Social Sciences (SPSS 21.0) and statistical significance was set at $\mathrm{p}<.05$. Before analyses, hypothesis of normality was examined for the scores obtained from total scales and subscales via the Shapiro-Wilk test ( $<50$ participants). Additionally, the normal distribution of data was checked using coefficients of skewness and kurtosis, and \pm 1 interspace was accepted as the cut-off score. The data showing a normal distribution were analysed using parametric statistical methods (independent \& paired samples t-test), and when the data was not normally distributed the data were analysed using non-parametric statistical methods (Mann Whitney U-test, Wilcoxon signed rank test for paired samples). The reliability and validity of the instrument was tested using Cronbach's Alpha, Pearson and Spearman correlations coefficients.

\section{FINDINGS}

\section{Reliability Analysis}

Cronbach's $\alpha$ coefficients were calculated for pre- and post measures of the PKBS-2. The results (Table 2) indicated satisfactory levels for the two main scales as well as for the five subscales. These results are similar to the internal consistency of social skills (.94) and problem behavior (.97) of the Greek language version of PKBS-2 (Chiou, 2016). Internal consistency scores for the original PKBS-2 supported these results with respect to social skills at .96 and problem behavior at .97 (Merrell, 2002). 
Table 2

Pre- and Post-Measures Cronbach's a Coefficients

\begin{tabular}{lll}
\hline $\begin{array}{l}\text { scales and subscales } \\
\text { of PKBS-2 }\end{array}$ & $\begin{array}{l}\text { Cronbach 's } \alpha \\
\text { Pre measures (T1) }\end{array}$ & Post measures (T2) \\
\hline Social Skills (34 items) & 0.95 & 0.94 \\
\hline Social Cooperation (12 items) & 0.94 & 0.91 \\
\hline Social Interaction (11 items) & 0.93 & 0.91 \\
\hline Social Independence (11 items) & 0.91 & 0.91 \\
\hline Problems Behavior (42 items) & 0.96 & 0.95 \\
\hline Externalizing Problems (27 items) & 0.98 & 0.97 \\
\hline Internalizing Problems (15 items) & 0.93 & 0.91 \\
\hline
\end{tabular}

\section{Correlations}

Construct validity was further investigated by computing the Pearson (r) and Spearman $\left(\mathrm{r}_{\mathrm{ho}}\right)$ correlations coefficients among the scales and subscales, at the initial measurement. More specifically, the correlations analysis (Table 3) indicated that the social skills subscales had positive correlations with each other and negative correlations with the subscales of behavioral problems, which also had positive correlations between them.

Table 3

Correlations among PKBS-2 Scales \& Subscales Scores at the Initial Measurement

\begin{tabular}{|c|c|c|c|c|c|c|c|}
\hline & A1 & $\mathrm{A} 2$ & A3 & A & $\mathrm{B} 1$ & $\mathrm{~B} 2$ & $\mathrm{~B}$ \\
\hline A1Social Cooperation & 1.00 & $\mathrm{r}_{\mathrm{ho}} .56^{*}$ & $\mathrm{r}_{\mathrm{ho}} \cdot 41 *$ & $\mathrm{r}_{\mathrm{ho}} \cdot 77 *$ & $\mathrm{r}_{\mathrm{ho}^{-}}-82^{*}$ & $\mathrm{r}_{\mathrm{ho}^{-} \cdot 28}$ & $\mathrm{r}_{\mathrm{ho}}-.79 *$ \\
\hline A2Social Interaction & & 1.00 & $\mathrm{r}_{\mathrm{ho}} .70 *$ & r.89* & $\mathrm{r}_{\mathrm{ho}^{-} .41 *}$ & $\mathrm{r}_{\mathrm{ho}}-.17$ & $\mathrm{r}_{\mathrm{ho}^{-} .41 *}$ \\
\hline A3Social Independence & & & 1.00 & $\mathrm{r}_{\mathrm{ho}} .82 *$ & $\mathrm{r}_{\mathrm{ho}}-.20$ & $\mathrm{r}_{\mathrm{ho}}-60 *$ & $\mathrm{r}_{\mathrm{ho}}-.46^{*}$ \\
\hline ASocial Skills & & & & 1.00 & $\mathrm{r}_{\mathrm{ho}-.57 *}$ & $\mathrm{r}_{\mathrm{ho}}-.41 *$ & $\mathrm{r}_{\mathrm{ho}}-.65^{*}$ \\
\hline B1Externalizing Problems & & & & & 1.00 & $\mathrm{r}_{\mathrm{ho}} .29$ & $\mathrm{r}_{\mathrm{ho}} .88 *$ \\
\hline B2Internalizing Problems & & & & & & 1.00 & $\mathrm{r}_{\mathrm{ho}} \cdot 66^{*}$ \\
\hline BProblems Behavior & & & & & & & 1.00 \\
\hline
\end{tabular}

$* \mathrm{p}<0.05$

Moreover, in the light of the data obtained from Table 3 the range of correlations between the Social Skills subscales is between .41 and .70 , whereas the subscale to total score correlations range from .77 to .89 . For the Problem Behavior subscale scores, the correlation is .29 , whereas the subscale to total score correlations range from .66 to 88 . According to Merrell (2002), these patterns of correlations provide additional evidence for the construct validity of the PKBS-2 and suggest that the subscales are all strongly related to the general constructs being measured and are at the same time somewhat independent from each other, measuring specific facets of social skills or problem behavior. As a final measure of this type of construct validity, the correlation between the total scores of the two PKBS-2 scales (Social Skills and Problem Behavior) was computed. The resulting coefficient of -.65 is both negative and moderate, suggesting that children with higher levels of social skills had lower levels of problem behavior. Thus, this result is in line with Merrell's (2002) ( $\mathrm{r}=-.56)$ and Chiou's (2016) (r=-.71).

\section{Gender Differences at the Initial Measurement}

At the beginning, the Mann-Whitney $U$ test analysis was held to find out if there were statistically significant differences between the boys and girls at the initial measurement. 
The results (Table 4) showed that significant differences were found on total and all subscales of social skills, except in social cooperation $(\mathrm{U}=117.000, \mathrm{p}=0.063)$ between girls and boys at the initial measurement. Teachers scored girls higher than boys in social interaction $(\mathrm{p}<0.05)$, social independence $(\mathrm{p}<0.05)$ and Social Skills $(\mathrm{p}<0.05)$. Conversely, teachers scored boys significantly higher than girls in the externalizing $(\mathrm{p}<0.05)$ and internalizing problem behaviors $(\mathrm{p}<0.05)$. Furthermore, significant differences were determined for total problem behavior $(\mathrm{p}<0.05)$.

Table 4

Mann Whitney U Test Results of Scores the Children Obtained from PKBS-2 with Regard to Gender at the Initial Measurement

\begin{tabular}{|c|c|c|c|c|c|c|}
\hline $\begin{array}{l}\text { Scales and subscales } \\
\text { Social Skills }\end{array}$ & Gender & $\mathrm{N}$ & Mean Rank & Sum Rank & $\mathrm{U}$ & $\mathrm{p}$ \\
\hline \multirow{2}{*}{ Social Cooperation } & Girls & 14 & 25.14 & 352.00 & \multirow{2}{*}{117.000} & \multirow{2}{*}{0.063} \\
\hline & Boys & 26 & 18.00 & 468.00 & & \\
\hline \multirow{2}{*}{ Social Interaction } & Girls & 14 & 28.96 & 405.50 & \multirow{2}{*}{$63.500^{*}$} & \multirow{2}{*}{0.001} \\
\hline & Boys & 26 & 15.94 & 414.50 & & \\
\hline \multirow{2}{*}{ Social Independence } & Girls & 14 & 27.54 & 385.50 & \multirow{2}{*}{$83.500 *$} & \multirow{2}{*}{0.005} \\
\hline & Boys & 26 & 16.71 & 434.50 & & \\
\hline \multirow{2}{*}{ Total Score } & Girls & 14 & 29.25 & 409.50 & \multirow{2}{*}{$59.500 *$} & \multirow{2}{*}{0.001} \\
\hline & Boys & 26 & 15.79 & 410.50 & & \\
\hline \multicolumn{7}{|l|}{ Problems Behavior } \\
\hline \multirow{2}{*}{ Externalizing Problems } & Girls & 14 & 14.64 & 205.00 & \multirow{2}{*}{$100.000 *$} & \multirow{2}{*}{0.019} \\
\hline & Boys & 26 & 23.65 & 615.00 & & \\
\hline \multirow{2}{*}{ Internalizing Problems } & Girls & 14 & 14.43 & 202.00 & \multirow{2}{*}{$97.000 *$} & \multirow{2}{*}{0.015} \\
\hline & Boys & 26 & 23.77 & 618.00 & & \\
\hline \multirow{2}{*}{ Total Score } & Girls & 14 & 14.11 & 197.50 & \multirow{2}{*}{$92.500^{*}$} & \multirow{2}{*}{0.011} \\
\hline & Boys & 26 & 23.94 & 622,50 & & \\
\hline
\end{tabular}

$* \mathrm{p}<0.05$

\section{Differences between experimental and control group at the initial measurement}

In order to determine equivalence of the two research groups before the program implementation occurred, a pretest was administered to both groups and the results are presented in Table 5 below.

Table 5

Means and Standard Deviations (SD) of Social Skills and the Behavioral Problems of both Groups at the Initial and Final Measurements

\begin{tabular}{lllll}
\hline \multirow{2}{*}{$\begin{array}{l}\text { Factors } \\
\text { Scales \& }\end{array}$} & Experiment group & \multicolumn{3}{l}{ Control group } \\
\cline { 2 - 5 } & $\begin{array}{l}\text { Initial } \\
\text { Mean }(\mathrm{SD})\end{array}$ & $\begin{array}{l}\text { Final } \\
\text { Mean }(\mathrm{SD})\end{array}$ & $\begin{array}{l}\text { Initial } \\
\text { Mean }(\mathrm{SD})\end{array}$ & $\begin{array}{l}\text { Final } \\
\text { Mean }(\mathrm{SD})\end{array}$ \\
\hline Social Skills & $79.80( \pm 14.99)$ & $85.35( \pm 10.65)$ & $81.70( \pm 13.44)$ & $83.45( \pm 13.17)$ \\
\hline Social Cooperation & $29.90( \pm 5.77)$ & $31.30( \pm 4.08)$ & $31.95( \pm 4.49)$ & $32.40( \pm 4.23)$ \\
\hline Social Interaction & $23.10( \pm 6.55)$ & $25.05( \pm 5.25)$ & $23.25( \pm 5.80)$ & $23.90( \pm 5.96)$ \\
\hline Social Independence & $26.80( \pm 5.43)$ & $29.00( \pm 4.09)$ & $26.50( \pm 5.58)$ & $27.15( \pm 5.12)$ \\
\hline Problems Behavior & $24.30( \pm 21.65)$ & $19.10( \pm 16.55)$ & $11.50( \pm 11.20)$ & $11.05( \pm 10,87)$ \\
\hline Externalizing Problems & $17.25( \pm 19.09)$ & $13.65( \pm 13.98)$ & $5.75( \pm 8.32)$ & $5.65( \pm 8.18)$ \\
\hline Internalizing Problems & $7.05( \pm 6.02)$ & $5.45( \pm 4.38)$ & $5.75( \pm 7.05)$ & $5.40( \pm 6.53)$ \\
\hline
\end{tabular}


The results in Table 5 show that there were differences in the mean scores between pupils of experimental group and pupils of control group in all factors of social skills and behavior problems. To determine if these differences were statistically significant or not, independent samples t-test and Mann-Whitney U test were utilized due to the results of preliminary testing for normality. Prior to that, the presupposition of variances homogeneity of the two groups was scrutinized by Levin test in the case of independent samples t-test. The results of the statistical test are presented in Table 6.

Table 6

Pre-test Results of the Participants in the Experimental and Control Groups

\begin{tabular}{lll}
\hline Factors & Test & $\mathrm{p}$ \\
\hline Social Skills & Independent samples & 0.675 \\
\hline Social Cooperation & Mann-Whitney U & 0.319 \\
\hline Social Interaction & Independent samples & 0.939 \\
\hline Social Independence & Mann-Whitney U & 0.892 \\
\hline Problems Behavior & Mann-Whitney U & 0.028 \\
\hline Externalizing Problems & Mann-Whitney U & 0.017 \\
\hline Internalizing Problems & Mann-Whitney U & 0.237 \\
\hline
\end{tabular}

From the results it appeared that any differences in 'Social Skills' $\left(\mathrm{t}_{(38)}=0.422, \mathrm{p}>.05\right)$, 'Social Cooperation' (U=163.500, $\mathrm{p}>.05)$, 'Social Interaction' $\left(\mathrm{t}_{(38)}=-0.077, \mathrm{p}>.05\right)$, 'Social Independence' (U=195.000, $\mathrm{p}>.05)$ and 'Internalizing Problems' (U=156.500, $\mathrm{p}>.05)$ factors were not statistically significant. It means that there was balanced distribution between the groups on level of social skills and internalizing problem behaviors before intervention. Most children in both the experimental and the control groups scored scores that ranked them at the average social skill level. However, according to the results of the 'Externalizing Problems' $(\mathrm{U}=112.500, \mathrm{p}=.017)$ subscale and total 'Problems Behavior' $(\mathrm{U}=119.500, \mathrm{p}=.028)$ showed statistical significant differences among the groups. More specifically, experiment group exhibited significantly higher scores on externalizing problems and total problems behavior compared with the control group in the initial (pre) measurement.

\section{Findings after the implementation of the intervention program}

In Table 5 above, it can be seen that after the implementation of the 4-week structured, playful activity program, has been a quantitative advance at both groups in the investigated social behaviors. Experimental group increased their total social skills from an average of 79.80 to 85.35 and control group from 81.70 to 83.45 . Also, experimental group reduced their total behavior problems from an average of 24.30 to 19.10 and control group from 11.50 to 11.05 .

To determine if these changes were statistically significant or not, seven paired sample ttest (pre- and post-measures) were run to compare effect of intervention on social skills and problems behavior of experimental group. The results showed that there were significant difference between scores of experimental group before and after intervention in 'Social Skills' $\left(\mathrm{t}_{(19)}=-3.573, \mathrm{p}=.002\right)$, 'Social Cooperation' $\left(\mathrm{t}_{(19)}=-2.483\right.$, $\mathrm{p}=.023)$, 'Social Interaction' $\left(\mathrm{t}_{(19)}=-3.157, \mathrm{p}=.005\right)$, 'Social Independence' $\left(\mathrm{t}_{(19)}=-3.317\right.$, $\mathrm{p}=.004)$, 'Externalizing Problems' $\left(\mathrm{t}_{(19)}=2.241, \mathrm{p}=.037\right)$, 'Internalizing Problems' 
$\left(\mathrm{t}_{(19)}=2.373, \mathrm{p}=.028\right)$ and total 'Problems Behavior' $\left(\mathrm{t}_{(19)}=3.001, \mathrm{p}=.007\right)$. Similar, to test whether change in the performance of the control group social skill's and behavioral problems' within the four-week period between measurements were statistically significant or not, paired sample t-test and Wilcoxon signed rank test were run. The results showed significant effects of changes in 'Social Skills' $\left(\mathrm{t}_{(19)}=-3.684, \mathrm{p}=.002\right)$, 'Social Cooperation' $\left(\mathrm{t}_{(19)}=-2.131, \mathrm{p}=.046\right)$, 'Social Interaction' $\left(\mathrm{t}_{(19)}=-2.942, \mathrm{p}=.008\right)$, 'Internalizing Problems' $(\mathrm{Z}=-2.070, \mathrm{p}=.038)$ and total 'Problems Behavior' $\left(\mathrm{t}_{(19)}=2.932\right.$, $\mathrm{p}=.009)$, except in 'Social Independence' $\left(\mathrm{t}_{(19)}=-1.990, \mathrm{p}=.061>.05\right)$ and 'Externalizing Problems' $\left(\mathrm{t}_{(19)}=1.453, \mathrm{p}=.163>.05\right)$

The last statistical analysis had to do with post-test differences between experimental and control group, which tested using independent samples t-test and Mann-Whitney U test. From the results it appeared that any differences in 'Social Skills' $\left(\mathrm{t}_{(38)}=0.502\right.$, $\mathrm{p}=.619)$, 'Social Cooperation' $(\mathrm{U}=170.000, \mathrm{p}=.410)$, 'Social Interaction' $\left(\mathrm{t}_{(38)}=0.647\right.$, $\mathrm{p}=.521)$, 'Social Independence' $(\mathrm{U}=160.000, \mathrm{p}=.276)$, 'Internalizing Problems' $(\mathrm{U}=167.500, \mathrm{p}=.377)$ and total 'Problems Behavior' $(\mathrm{U}=129.500, \mathrm{p}=.056)$, factors were not statistically significant. However, according to the results of the 'Externalizing Problems' (U=116.500, $\mathrm{p}=.023)$, showed statistical significant differences among the groups. More specifically, experimental group had a bigger progress than control group in the final (post) measurement. In conclusion, it was observed that the intervention had positive effects on the treatment group' externalizing problems.

\section{DISCUSSION}

The purpose of this study was to investigate the effect of a playful activity structured program on the development of social skills in preschool aged children (4-6 years) during break time in the schoolyard of kindergarten. The overall picture, deriving from the results, showed that the implementation of a playful activity structured program had positive impact and improved various social behaviors and skills of preschoolers. These results are in agreement with recent research findings (Loukatari et al., 2014; Sparris et al., 2016) that also showed that the structured playfulness rest hour constitute an ideal field for the development of children's social skills. After the realization of the intervention program, the results of the statistical analysis indicated that there were significant differences found between the children's PKBS-2 pre and posttest scores of the experiment group in all subscales. Students, who took part in the program increased their social skills and reduced their behavior problems. However, there were no significant statistical differences between students' experimental group and students' control group in their social skills after their participation in the intervention program. On the contrary, treatment group performed better than those in the control group on the externalizing problems after the end of the program. It should be noted that at baseline, the intervention group had rated higher in these problems than control group. This outcome is very important, because it is widely understood that externalizing behavioral problems of young children, if left untreated, may evolve into serious conduct problems, disruptive behavior disorders and antisocial and delinquent behaviors (Shaw et al., 1994). Moreover, this finding confirmed that a structured program of playful activities 
during breaks in the yard positively improved certain behavioral problems of kindergarten students.

It was also observed that PKBS-2 posttest scores of the control group were significantly higher compared to their pretest scores. That means the prominent increase in the posttest scores of experimental group in social skills can be due the contribution of the preschool education and the daily educational opportunities. Dinc and co-authors (Dinc et al., 2011) performed a study in which they examined the social development levels of preschool age pupils 4-5 years and they showed that the social development levels increased as the duration of the preschool education increased. Besides, in the same study, teachers stated that preschool training contributed to the social development of children. Furthermore, the effects of the other factors such as parents and teacher attitudes on the social development of children should not be ignored. Koçak and Tepeli (2004) examined the social relationships and cooperation behaviors of 4-5 years old children who were attending the preschool institution and they showed that mother's educational status and socio-economic status influenced the cooperation and social relationships of children.

As concerns the correlation analyses among the scales of PKBS-2, at the initial measurement, the results showed that social skills have negative and moderate statistic relation with problem behavior. The results of the present study are consistent with the findings of Merrell (2002) and Chiou (2016) who confirmed that the social skills and problem behavior are two theoretically separate, but related domains, which means that low levels of social skills underlie behavioral problems. The findings regarding gender differences on social skills and problem behavior of the present study provides further evidence for the interpretation of this relation. Also, Najaka and co-authors (2001), several years ago, drew the same conclusions with the present study, who supported that social skills and behavioral problems to be negatively correlated. According to the results of the gender differences, the findings indicated that female kindergartners were rated as having higher scores in social skills (although there were no statistically significant differences between two sexes in cooperation) and lower on problem behaviors, whereas, boys were rated higher on the problem behaviors factor and lower on social skills than girls. Considering the history of the research, several previous studies (DiPrete \& Jennings, 2012; Gomes \& Pereira, 2014; StØrksen et al., 2015; Vahedi et al., 2012), have recorded significant differences in the social skills between the two genders, which argued that boys are more physically active, more committed to competitive activities that involve high risk and exhibit more anger and aggression than girls. In contrast, girls engage in more dyadic play than boys or prefer the company of their mostly female preschool teachers to boys and they seem to be more eager to develop their social skills and control their behavior in order to avoid their teachers' criticism. A somewhat surprising finding in the present study, which is not in accordance with those of Chiou (2016) and Maguire et al. (2016), was that boys were rated as having significant higher scores in internalizing problems. However, overlooking these problems does not result in their diminishment, and if left unidentified and untreated, internalizing disorders may evolve into chronic and debilitating mental health problems 
(Poulou, 2015; Thomas \& Guskin, 2001). Considering these facts, it becomes clear the early detection in children's social behavior.

\section{CONCLUSION}

The primary goal of this study was to examine the possible effects of a 4-week structured, playful activity program on social skills and behavior problems in children preschool aged children (4-6 years). After the 4-week structured playful activity program during break time in the schoolyard of kindergarten, the results showed an overall improvement on social behavior for the intervention pupils. The conclusions drawn from this study concerning the intervention method strengthen the current literature in relation to positive effect of the mediating role of adults in children's free play. These conclusions were drawn from the analysis of data, collected by a behavior rating scale and videotaped recordings of 40 students from a single Greek kindergarten. Subsequent investigations with larger sample are more likely to confirm or revise these conclusions. Moreover, in this study, the social skill levels of children were assessed with the help of the perspectives of teachers. It can be recommended to perform a study in which mother, father and teacher opinions are collectively evaluated and qualitative data should be also considered apart from the quantitative data. Nevertheless, it is important that through such procedures of the application of measurements such as those of the present research it is carried out an early detection of difficulties and the teacher is able to identify the particular social-developmental needs of each child, and then to design appropriate developmental intervention playfulness programs for the confronting of the difficulties and the appropriate support.

\section{REFERENCES}

Abdi, B. (2010). Gender differences in social skills, problem behaviours and academic competence of Iranian kindergarten children based on their parent and teacher ratings. Procedia-Social and Behavioral Sciences, 5, 1175-1179.

Arnold, D. H., Kupersmidt, J. B., \& Voegler-Lee, M. E. (2012). The association between preschool children's social functioning and their emergent academic skills. Early Childhood Research Quarterly, 27(3), 376-386.

Berry, D. J., \& O'Connor, E. (2010). Behavioral risk, teacher-child relationships, and social skill development across middle childhood: A child-by-environment analysis of change. Journal of Applied Developmental Psychology, 31(1), 1-14.

Bodrova, E., \& Leong, D. J. (2015). Vygotskian and Post-Vygotskian Views on Children's Play. American Journal of Play, 7(3), 371-388.

Chiou, V. (2016). The promotion of mental health among preschoolers aged 4-6 years old: The implementation of I Can Problem Solve Program in Greek kindergarten schools (Unpublished doctoral dissertation). Department of Pre-school Education and Educational Design, University of the Aegean, Rhodes, Greece. (In Greek). Retrieved from https://www.didaktorika.gr/eadd/handle/10442/38459. 
Cross-Curricular Program Framework (2003). Pedagogical Institute, Government Gazette 303 and 304 /13-3-2003, B, volumes A and B. (In Greek)

Denham, S. A. (2006). Social-emotional competence as support for school readiness: What is it and how do we assess it? Early Education and Development, 17(1), 57-89.

Dinc, F. D., Uluoz, E., \& Sevimli, D. (2011). Opinions on the families about of the children's of the sports and physical activity routing. E-Journal of New World Sciences Academy, 6(2), 93-102.

DiPrete, T. A., \& Jennings, J. L. (2012). Social and behavioral skills and the gender gap in early educational achievement. Social Science Research, 41(1), 1-15.

Domitrovich, E. C., Cortes, C. R., \& Greenberg, T. M. (2007). Improving young children's social and emotional competence: A randomized trial of the preschool "PATHS" curriculum. The Journal of Primary Prevention, 28, 67-91.

Elliot, S. N., \& Gresham, F. M. (1987). Children's social skills: Assessment and classification practices. Journal of Counselling and Development, 66, 96-99.

Gerrish, K., \& Lacey, A. (2010). The research process in nursing. United Kingdom: John Wiley \& Sons.

Gomes, R. M. S., \& Pereira, A. S. (2014). Influence of age and gender in acquiring social skills in Portuguese preschool education. Psychology, 5(2), 99-103.

Gregoriadis, A., Grammatikopoulos, V., \& Zachopoulou, E. (2013). Evaluating preschoolers' social skills: the impact of a physical education program from the parents' perspective. International Journal of Humanities and Social Science, 3(10), 40-51.

Gulay, H. (2011). School adjustment and peer relationships of 5-6 years old children. Electronic Journal of Social Sciences, 10(36), 1-10.

Koçak, N., \& Tepeli, K. (2004). Examination of the social skills and cooperative behaviors in 4-5-year-old children in terms various variables. Marmara University 1st International Pre-School Education Congress Report Book Volume II (pp. 9-21). Istanbul: Ya-Pa Publishing.

Landau, S., \& Milich, R. (1990). Assessment of children's social status and peer relations. In A. M. LaGreca (Ed.), Through the eyes of the child (pp. 259-291). Boston: Allyn \& Bacon.

Langeveld, J. H., Gundersen, K. K., \& Svartdal, F. (2012). Social competence as a mediating factor in reduction of behavioral problems. Scandinavian Journal of Educational Research, 56(4), 381-399.

Lindsey, E. W. (2002). Preschool children's friendships and peer acceptance: Links to social competence. Child Study Journal, 32(3), 145-156. 
Loukatari, P., Matsouka, O., Grammatikopoulos, V., \& Albanidis, E. (2014). Impact of Intervention programmes on kindergarten children's social skills: Theoretical framework and literature review. Journal Educational Circle, 2(2), 57-71. (In Greek).

Maguire, L. K., Niens, U., McCann, M., \& Connolly, P. (2016). Emotional development among early school-age children: Gender differences in the role of problem behaviours. Educational Psychology, 36(8), 1408-1428.

McClelland, M. M., \& Morrison, F. J. (2003). The emergence of learning-related social skills in preschool children. Early Childhood Research Quarterly, 18(2), 206-224.

McWayne, C. M., Cheung, K., Green Wright, L. E., \& Hahs-Vaughn, D. L. (2012). Patterns of school readiness among head start children: Meaningful within-group variability during the transition to kindergarten. Journal of Educational Psychology, 104(3), 862-878.

Merrell, K. W. (2008). Behavioral, social and emotional assessment of children and adolescents. Mahwah, New Jersey: Lawrence Erlbaum Associates.

Merrell, K. W. (2002). Preschool and kindergarten behavior scales (PKBS-2) examiner's manual. Texas: Pro.ed.

Merrell, K. W. (2001). Assessment of children's social skill: recent developments, best practices and new directions. Exceptionality, 9, 3-18.

Merrell, K. W., \& Gimpel, G. A. (2014). Social skills of children and adolescents: Conceptualization, assessment, treatment. New York, NY: Psychology Press.

Michelson, L., Sugai, D. P., Wood, R. P., \& Kazdin, A. E. (2013). Social skills assessment and training with children: An empirically based handbook. New York, NY: Springer Science \& Business Media.

Najaka, S. S., Gottfredson, D. C., \& Wilson, D. B. (2001). A meta-analytic inquiry into the relationship between selected risk factors and problem behavior. Prevention Science, 2, 257-271.

Oades-Sese, G. V., Esquivel, G. B., Kaliski, P. K., \& Maniatis, L. (2011). A longitudinal study of the social and academic competence of economically disadvantaged bilingual preschool children. Developmental Psychology, 47(3), 747-764.

Oden, S. L., \& Asher, S. R. (1977). Coaching children in social skills for friendship making. Child Development, 48, 496-506.

Ogden, T. (2011). Sosial ferdighetsopplæring for barn og ungdom. Tidskrift for Norsk Psykologiforening, 48, 64-68.

O’ Rourke, K., \& Worzbyt, J. C. (1996). Support groups for children. New York, NY: Routledge.

Poulou, M. S. (2015). Emotional and Behavioural Difficulties in Preschool. Journal of Child and Family Studies, 24(2), 225-236. 
Rimm-Kaufman, S. E., Pianta, R. C., \& Cox, M. J. (2000). Teachers' judgments of problems in the transition to kindergarten. Early Childhood Research Quarterly, 15(2), 147-166.

Rosenthal, M. K. (2003). Quality in early childhood education and care: A cultural context. European Early Childhood Education Research Journal, 11(2), 101-116.

Serpell, Z. N., \& Mashburn, A. J. (2012). Family-school connectedness and children's early social development. Social Development, 21(1), 21-46.

Shaw, D. S., Keenan, K., \& Vondra, J. I. (1994). Developmental precursors of externalizing behavior: Ages 1 to 3. Developmental Psychology, 30, 355-364.

Shure, M. B. (1980). Interpersonal problem solving in ten-year-olds (Final report @MH-27741). Washington, DC: National Institute of Mental Health.

Sparris, D., Kyriakou, C., Derri, V., \& Kouli, O. (2016). Social behaviors of pre-school children during in- and out-of-class play: similarities and differences. Exercise \& Society Journal of Sports Science, 57, 37-47. (In Greek).

Stagnitti, K. (2004). Understanding play: The implications for play assessment. Australian Occupational Therapy Journal, 51(1), 3-12.

StØrksen, I., Ellingsen, I. T., Wanless, S. B., \& McClelland, M. M. (2015). The influence of parental socioeconomic background and gender on self-regulation among 5year-old children in Norway. Early Education and Development, 26(5-6), 663-684.

Thomas, J. M., \& Guskin, K. A. (2001). Disruptive behavior in young children: what does it mean? Journal of the American Academy of Child \& Adolescent Psychiatry, 40(1), 44-51.

Vahedi, S., Farrokhi, F., \& Farajian, F. (2012). Social competence and behavior problems in preschool children. Iranian journal of Psychiatry, 7(3), 126-134.

Van Schoiack-Edstrom, L., Frey, K. S., \& Beland, K. (2002). Changing adolescents' attitudes about relational and physical aggression: An early evaluation of a school-based intervention. School Psychology Review, 31(2), 201-216.

Intergovernmental Panel on Climate Change. (2014). Summary for policymakers. In Climate change 2013 - the physical science basis: Working group I contribution to the fifth assessment report of the intergovernmental panel on climate change (pp. 1-30). Cambridge: Cambridge University. doi:10.1017/CBO9781107415324.004.

Wildenger, L. K., \& McIntyre, L.L. (2012). Investigating the relation between kindergarten preparation and child socio-behavioral school outcomes. Early Childhood Education Journal, 40(3), 169-176. 